\title{
Inflammatory fibroid polyp of the ileum presenting with small bowel obstruction in an adult patient: a case report
}

Toygar Toydemir

\begin{abstract}
Introduction: Inflammatory fibroid polyps are rare benign tumors of the gastrointestinal tract with the gastric antrum being the most common site, followed by the ileum. Histogenesis is still unknown and controversial. Inflammatory fibroid polyps are one of the rare benign conditions leading to intestinal obstruction in adults.

Case presentation: A 54-year-old Caucasian man presented with acute abdomen pain and a two month history of intermittent cramping and lower abdominal pain. Computed tomography imaging demonstrated a partial intestinal obstruction in the location of the terminal ileum. An ileo-ileal intussusception due to a mass lesion $15 \mathrm{~cm}$ proximal to the caecum was found on exploratory laparotomy. Intussusception was spontaneously reduced during exploration and a wedge resection was performed to the affected bowel segment. Histopathologic examination showed the mass to be an inflammatory fibroid polyp.
\end{abstract}

Conclusion: Although inflammatory fibroid polyps are rare and benign, in the case of intestinal obstruction the only solution is a surgical approach.

\section{Introduction}

Intussusception is an uncommon cause of intestinal obstruction in adults [1]. Patients with intussusception present with either acute or chronic intermittent symptoms. The majority of adult intussusceptions occur due to malignant processes [2]. We report the case of an adult inflammatory fibroid polyp (IFP) confined to the terminal ileum which presented with acute symptoms and a repeated intussusception background history. The aim of this study is to remind that some very rare etiologies may be involved in adult intestinal obstructions.

\section{Case presentation}

A 54-year-old Caucasian, Turkish man presented to the emergency department with acute abdominal pain, nausea and vomiting and a two month history of intermittent lower abdominal pain. There was no history of previous abdominal surgery, smoking or alcohol consumption.

Correspondence: toygartoydemir@hotmail.com

Department of General Surgery, İstanbul Surgery Hospital, Ferah sokak no:18 nişantaşı, 34365 İstanbul/Turkey
On examination, he was uncomfortable and had a heart rate of 110 , blood pressure $140 / 70 \mathrm{mmHg}$, and a temperature of $37.5^{\circ} \mathrm{C}$. Generalized abdominal pain was found on abdominal examination without signs of peritoneal irritation. Bowel sounds were normal. Laboratory analysis revealed 15,000 leukocytes with a prevalence of neutrophils. Other parameters were within the normal limits. Abdominal radiology demonstrated a few airfluid levels in the right lower quadrant. An intravenous and oral contrast computed tomography showed partial intestinal obstruction in the terminal ileum without generalized small bowel dilatation.

An exploratory laparotomy was performed with the diagnosis of subacute intestinal obstruction. An intussusception with a mass lesion at its lead point approximately $15 \mathrm{~cm}$ proximal to the caecum was found. Intussusception was spontaneously reduced during exploration. Limited edema at the lead point of the bowel, was the only sign of the intussusception (Figures 1 and 2). A wedge resection was performed to the affected bowel segment. 


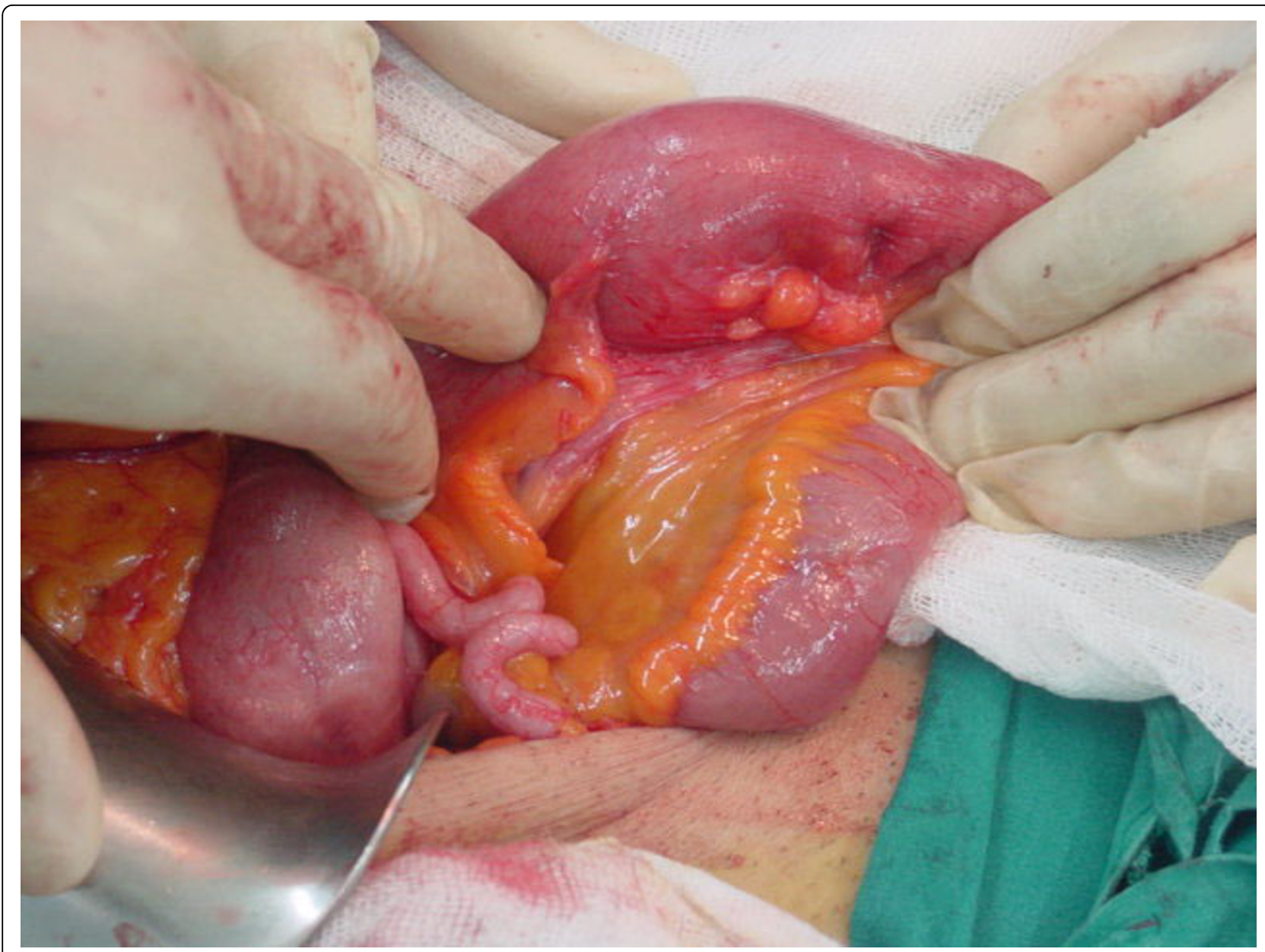

Figure 1 The lead point of intussusception.

Histopatologic examination showed proliferated vessel formations in a mixoid stroma and inflammatory cell infiltration consistent with IFP.

\section{Discussion}

IFPs are among the least common benign lesions of the gastrointestinal tract. They originate from the submucosa as a solitary or sessile lesion with an inflammatory basis. They can occur throughout the intestinal tract but most frequently in the gastric antrum and small bowel [3]. IFPs usually measure between two and $5 \mathrm{~cm}$ in diameter. However, there are also giant IFPs with a size of up to $12.5 \mathrm{~cm}$ in diameter having been reported [4]. IFP was first described by Vanek as a 'gastric submucosal granuloma with eosinophilic infiltration' in 1949 [5]. Histologically, IFPs are characterized by vascular and fibroblast proliferation with an eosinophilic inflammatory response. The underlying cause of IFP remains uncertain. Many factors have been suggested as a trigger such as intestinal trauma or eosinophilic gastroenteritis.
IFPs are usually asymptomatic, identified during endoscopy or laparotomy. When they are symptomatic the clinical presentation is determined by the anatomic location. Gastric IFPs may lead to pyloric obstruction or anemia with chronic bleeding [6]. When they arise from the small bowel, intussusception is the most common clinical finding.

Adult intussusception is a very rare condition, accounting for $1 \%$ of all adult bowel obstruction and occurs in only $5 \%$ to $16 \%$ of all intussuscepted cases [2]. About $70 \%$ to $90 \%$ of intussusception cases are due to benign or malignant neoplasms as a lead point and IFPs, lipomas and adenomas are the benign causes of intussusception [7]. However, it has been shown that intussusception can occur without significant pathological cause [8].

Unlike the more common idiopathic intussusception found in children, intussusception in adult patients still remains a surgical disease. The type of surgical procedure depends on the patient's medical history (previous operations, malignancy) and intra-operative findings [9]. 


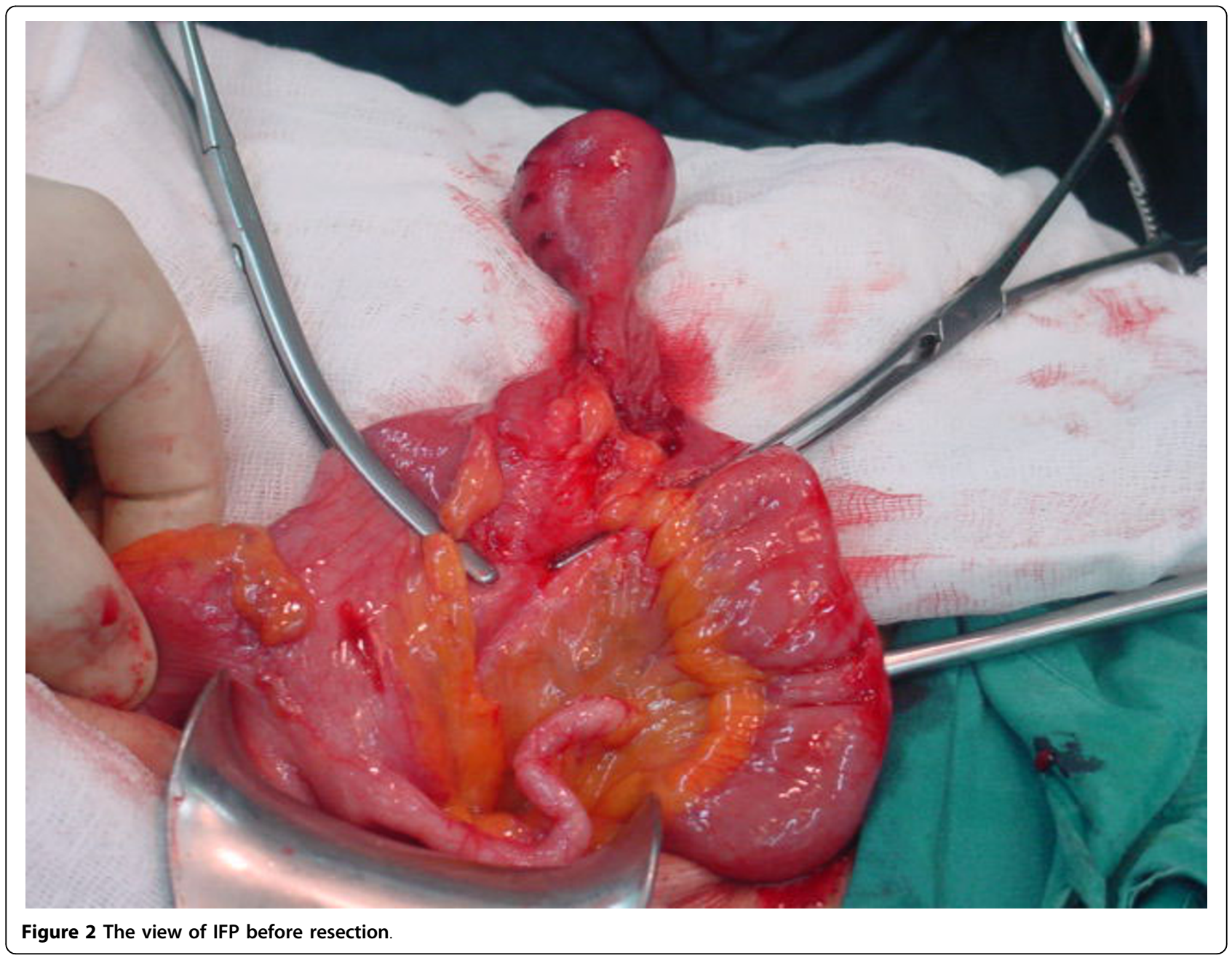

The optimal surgical management of intussusception in adult patients is influenced by two major factors: the presence of distinct malignancy and the local factors such as the degree of associated edema, and relative ischemia of the involved bowel. A wedge resection of affected bowel segment was performed in our case as very limited edema was observed at lead point of intussusception. However, attempts at local removal of polyps through a limited enterotomy, or by wedge resection through edematous bowel, may be dangerous and healthy bowel margins must be secure during segmental resection.

\section{Conclusions}

Intussusception is a very rare cause of adult intestinal obstruction and IFP is one of the least common causes of this rare condition. Although IFPs are benign lesions, surgical treatment is the only solution when they present with small bowel obstruction.

\section{Consent}

Written informed consent was obtained from the patient for publication of this case report and any accompanying images. A copy of the written consent is available for review by the Editor-in-Chief of this journal.

\section{Authors' contributions}

$\Pi T$ is the only author of this paper. $\Pi$ designed the study and wrote the manuscript.

\section{Competing interests}

The author declares that they have no competing interests.

Received: 29 January 2010 Accepted: 30 August 2010

Published: 30 August 2010

\section{References}

1. Huang BY, Warshauer DM: Adult intussusception: diagnosis and clinical relevance. Radiol Clin North Am 2003, 41:1137-1151.

2. Eisen LK, Cunningham JD, Aufses AH Jr: Intussusception in adults: institutional review. J Am Coll Surg 1999, 188:390-395.

3. Wysocki AP, Taylor G, Windsor JA: Inflammatory fibroid polyps of the duodenum: a review of the literature. Dig Surg 2007, 24(3):162-168. 
4. Harned RK, Buck JL, Shekitha KM: Inflammatory fibroid polyps of the gastrointestinal tract: Radiologic evaluation. Radiology 1992, 182:863-866

5. Vanek J: Gastric submucosal granuloma with eosinophilic infiltration. Am J Pathol 1949, 25(3):397-411.

6. Gonul II, Erdem O, Ataoglu O: Inflammatory fibroid polyp of the ileum causing intussusception: a case report. Turk J Gastroenterol 2004, 15:59-62.

7. Karamercan A, Kurukahvecioglu O, Yilmaz TU, Aygencel G, Aytaç B, Sare M: Adult ileal intussusception: an unusual emergency condition. Adv Ther 2006, 23:163-168.

8. Lvoff N, Breiman RS, Coakley FV, Lu Y, Warren RS: Distinguishing features of self-limiting adult small-bowel intussusception identified at CT. Radiology 2003, 227:68-72.

9. Yalamarthi S, Smith RC: Adult intussusception: case reports and review of literature. Postgrad Med J 2005, 81(953):174-177.

doi:10.1186/1752-1947-4-291

Cite this article as: Toydemir: Inflammatory fibroid polyp of the ileum presenting with small bowel obstruction in an adult patient: a case report. Journal of Medical Case Reports 2010 4:291.

\section{Submit your next manuscript to BioMed Central} and take full advantage of:

- Convenient online submission

- Thorough peer review

- No space constraints or color figure charges

- Immediate publication on acceptance

- Inclusion in PubMed, CAS, Scopus and Google Scholar

- Research which is freely available for redistribution

Submit your manuscript at www.biomedcentral.com/submit
C Biomed Central 